\title{
A wind tunnel method for screening the interaction between wind turbines in planned wind farms
}

\author{
Mats Sandberg ${ }^{1, *}$, Hans Wigö ${ }^{1}$, Leif Claesson ${ }^{1}$, Mathias Cehlin ${ }^{1}$ \\ ${ }^{1}$ University of Gävle, Gävle, Sweden \\ * Corresponding author. Tel: +46 26648139, Fax: +46 648181, E-mail: msg@HiG.se
}

\begin{abstract}
The energy captured by wind farms is reduced if there is an interaction between the individual turbines. In the paper a novel method for studying the interaction between wind turbines is presented. It is based on recording the static pressure on ground in a wind tunnel provided with wind turbine models.

The assumption is that the pressure distribution at ground reflects the pressure distribution at hub height. The pressure distribution at hub height is a result of the flow in the vicinity of the turbine.

The pressure at ground is recorded with a pressure plate provided with 400 pressure taps. The wind turbine model is a porous disk giving a non rotating wake.

At first the pressure response to one wind turbine is recorded. This is the reference case giving the characteristics of a non disturbed wind turbine. Its region of influence can therefore be determined. This provides important information on how to avoid any interaction between turbines. A nearby turbine should not be placed within the region of influence. In the paper we show how the pressure response varies with different distances between two turbines. The agreement between the static pressure on ground and at hub height has been tested by recording the static pressure at hub height with a small Prandtl tube.
\end{abstract}

Keywords: Wind farms, Wind tunnel, Pressure distribution on ground, Pressure distribution at hub height, Region of influence

\section{Introduction}

To benefit of economies of scale, wind turbines are arranged in wind farms. As wind energy capacity expands, the size of individual wind farms continues to increase requiring tens to hundreds of wind turbines typically arranged in a large array. While organizing wind turbines in wind farms help in reducing the cost of energy production they introduce another problem, aerodynamic interaction. One of the research challenges is to accurately model interactions between the individual turbines to accurately predict power output before wind farm construction. In a wind farm with $N$ turbines the wind farm efficiency is defined as

$\eta_{A}=\frac{E_{A_{i}}}{E_{T} N}$

Where $E_{A}$ is the annual energy captured by the wind farm and $E_{T}$ is the annual energy captured by one isolated turbine. If there were no aerodynamic interaction the energy captured by the wind farm would be $N E_{T}$ and the efficiency would subsequently be $100 \%$. Figure 1 shows a wind turbine with rotor diameter $D$. Array losses can be reduced by optimization of the downwind spacing and the cross wind spacing.

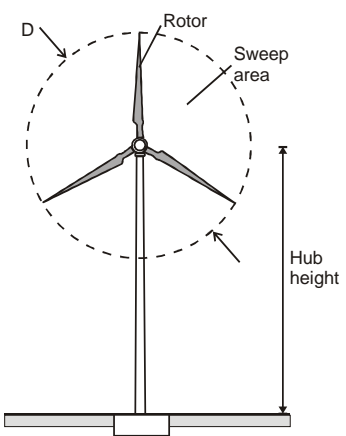

Fig. 1. Definition of some concepts 
Behind a wind turbine there is rotating wake with a velocity deficit with respect to the approaching free wind $U_{\infty}$. If we set the reference pressure (static pressure) in the undisturbed wind to zero there is an under pressure in the wake (compare Figure 5). After a relatively short distance there is pressure recovery. However the velocity deficit goes on for a long distance behind the turbine.

With a too short distance between wind turbines the wind turbines upstream will lower the exposed wind speed of the turbines downstream. Subsequently the power generated by the wind farm will be reduced. This calls for the need of methods for predicting the risk of interaction. Providing such methods in the planning process is the purpose of this research. The importance of accurate design models increases since the turbines gets larger and larger by time. If there is an interaction between wind turbines one can minimize the loss in power generated by suitable control of the wind turbines [1].

It is extremely difficult to predict the power output from wind farms, due to atmospheric turbulence, wind shear, changes in wind directions, wake effect from neighboring turbines etc. In recent times, CFD (Computational Fluid Dynamics) simulations have been performed on wind turbines. Recent wake studies based on CFD using various turbulence models have been presented by e.g. Ivanell [2], Sørensen et al. [3], and Wußow et al.[4]. CFD methods for simulating wake flows and wake interactions need to resolve many different length scales, ranging from the thickness of the blade boundary layer to the distance between the turbines. Hence, there are still limitations in CFD to simulate an entire park, due to computer limitations.

\subsection{Basic assumption behind the method}

Our approach for studying the aerodynamic interaction between individual wind turbines is based on the assumption that with a plain ground the static pressure distribution on the ground reflects the pressure distribution at hub. Aand the pressure distribution at the hub height reflects the air flow pattern at this height. For natural ventilation the relation between the static pressure in air and on the ground has been explored in [5]. The results were encouraging and are the impetus for this work.

\section{Methodology}

\subsection{Wind tunnel}

The experiments were conducted in the atmospheric boundary layer wind tunnel at University of Gävle. The pertinent details of the wind tunnel are shown in Figure 2. Within the empty wind tunnel there is a pressure gradient, see Fig 9. To equalize the pressure within the wind tunnel with the ambient pressure the wind tunnel is provided with a slot of width $6 \mathrm{~cm}$ located $255 \mathrm{~cm}$ downstream of the centre of the turning table. The slot is running along the whole perimeter of the wind tunnel.

During the tests the wind speed at half height in the test section was about $20 \mathrm{~m} / \mathrm{s}$. 


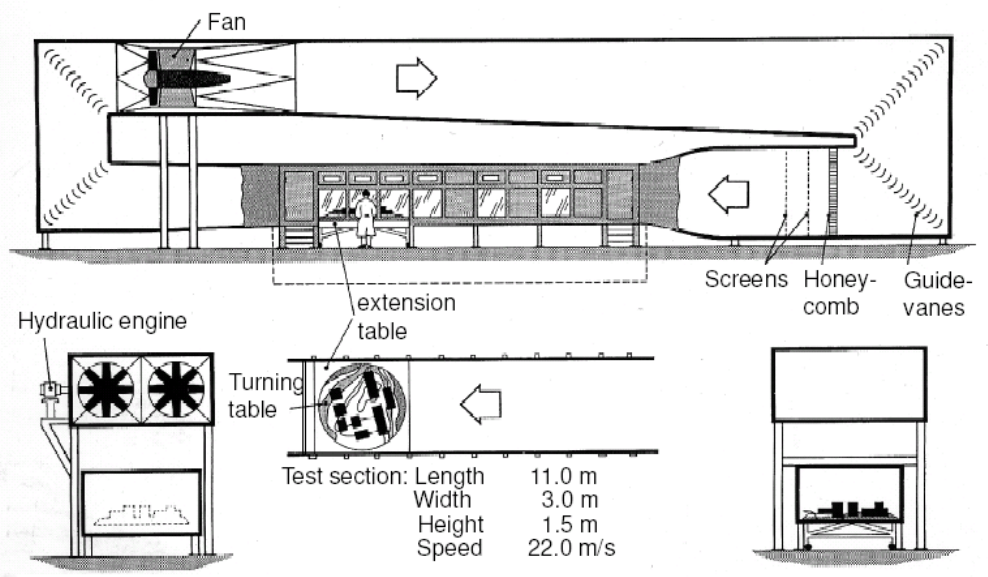

Fig. 2. Atmospheric boundary layer wind tunnel

\subsection{Wind turbine model}

The wind turbine model used in this study was in scale 1:2000 and had a diameter of $45 \mathrm{~mm}$ and the hub height was $45 \mathrm{~mm}$. This corresponds to a wind turbine with 90 meters diameter and a hub height of 90 meters. In the model the rotor where replaced by a porous disc, which was used to simulate the wake behind the wind turbine Medici \& Alfredsson [6] .The disc porosity was $42 \%$ and the corresponding drag coefficient was 0.85 . This value of the drag coefficient is approximately the same as the value obtained for a turbine at high tip speed ratios.

\subsection{Technique for measurement of static pressure at hub height and on the ground}

The static pressure at hub height (45mm above ground in the wind tunnel) was measured with a Prandtl tube of $3 \mathrm{~mm}$ diameter. The static pressure on ground was measured with a pressure plate provided with 400 pressure taps organized in a quadratic pattern with a distance of 37 $\mathrm{mm}$ between the centers of the taps, see Figure 3. The pressure was recorded with a pressure transducer connected to a scanner valve. Measuring the pressure in all 400 pressure taps takes about 5 hours

Figure 4 shows the wind tunnel with one wind turbine model placed on the pressure plate. In this picture the wind tunnel was provided with roughness elements and spires to generate a turbulent boundary layer. 


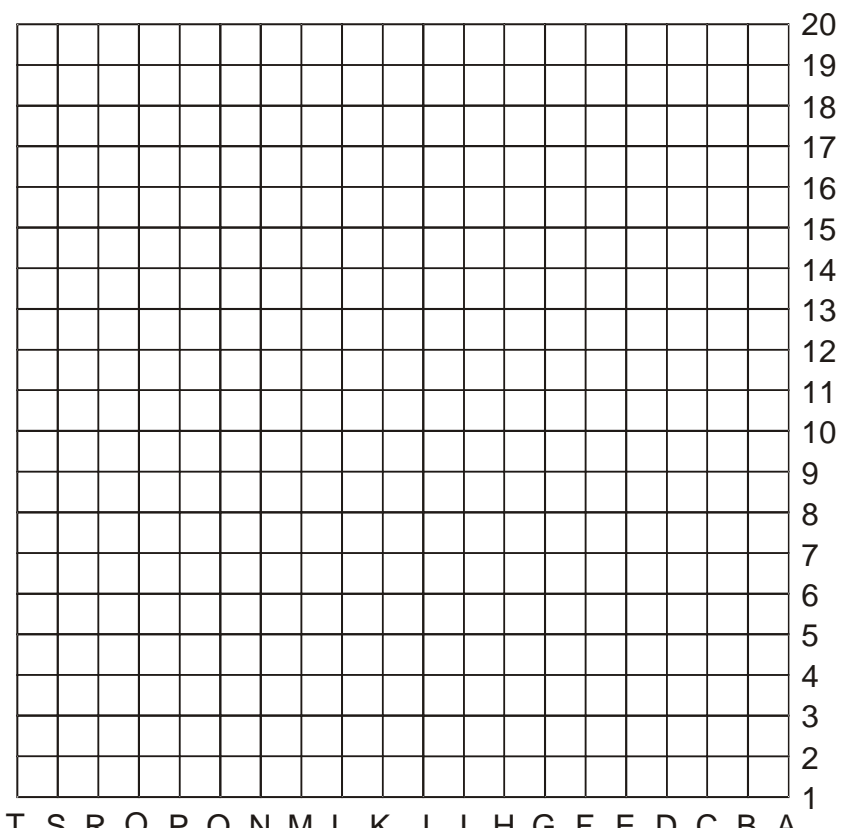

Fig. 3 Notation for the pressure plate

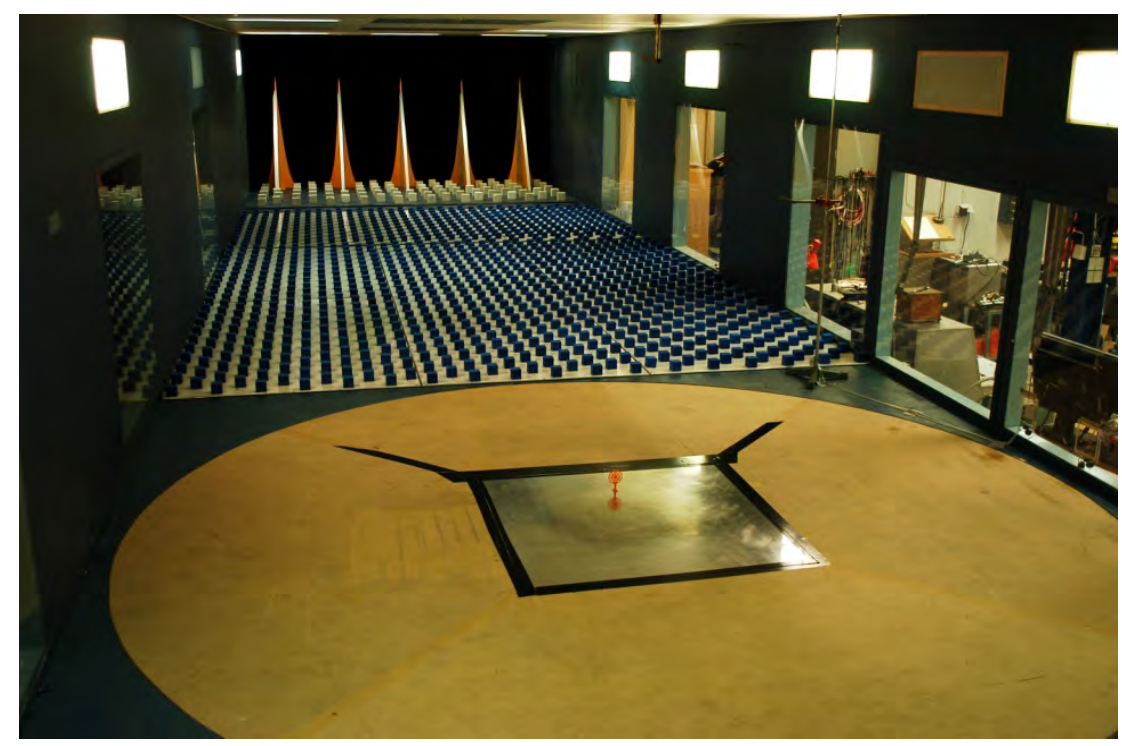

Fig. 4 Wind tunnel with one wind turbine model placed on the pressure plate along line 10 in Fig.3

To eliminate the effect of the pressure gradient along the wind tunnel a measurement was first made with an empty wind tunnel. These data were then subtracted from the pressure readings obtained with a turbine model present.

\section{Results}

\subsection{Pressure response on ground due to one wind turbine}

To begin with one wind turbine was placed on the pressure plate along line 10 in Figure 3 and the pressure was recorded. Figure 5 shows the recorded pressure (raw data) quantified as a pressure coefficient. 


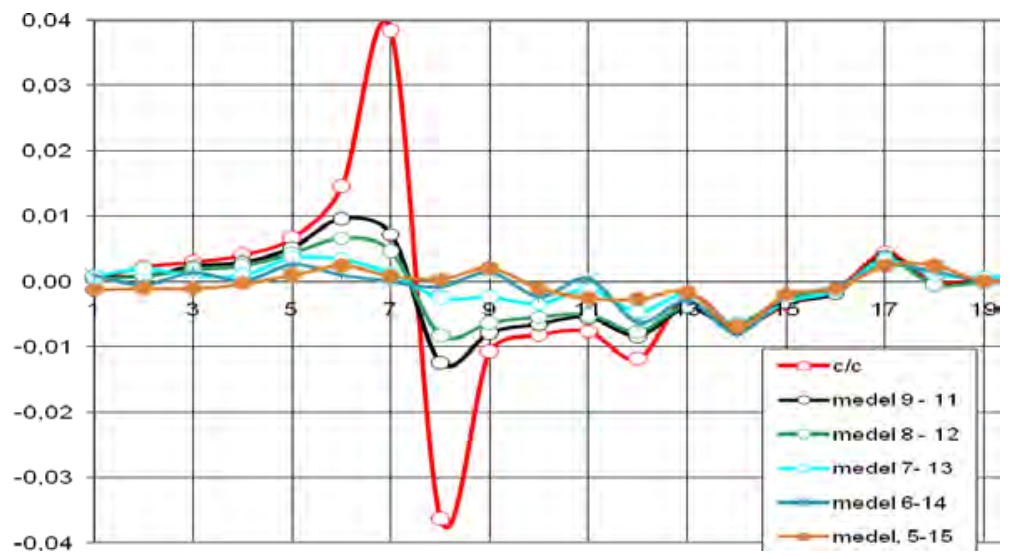

Fig. 5. Recorded pressure coefficients at different positions with one wind turbine on the pressure plate. $($ medel $=$ average $)$.

The pressure is shown as the pressure distribution along line 10 (center line) in Figure 3.. The pressures in the surroundings are shown as the mean value of the lines 9-11, 8-12, 7-13, 6-14 and 5-15 respectively .

Upwind the pressure reflects the deceleration of the flow when approaching the disk. The highest pressure corresponds to the stagnation pressure on a solid disk. Then there is an acceleration of the flow when passing through the openings of the disk. After reaching the minimum pressure in the wake the static pressure is recovered relatively fast.

\subsection{The region of influence of one wind-turbine}

The gray area in Figure 6 shows the region of influence, of a wind turbine located on the center line.

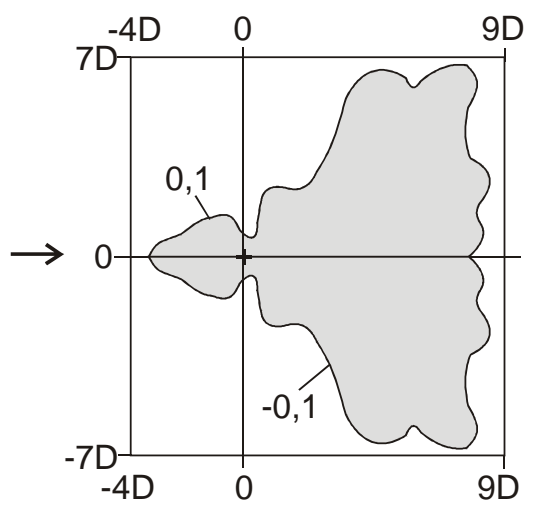

Fig. 6. Region of influence from one wind turbine located at the cross based on static pressure readings on the pressure plate. The pressure has been normalized with the highest pressure..

The region of influence on the upwind side is defined by the line representing $10 \%$ of the highest pressure ( 0.1 line) an on the downwind side by the line representing $-10 \%$ of the highest pressure (-0.1 line). The pressure has been normalized with the highest pressure which occurs just before the wind turbine. 


\subsection{An example of interaction between wind turbines}

The interaction between two wind turbines was explored by placing two wind turbines with a separation distance of $6.66 \mathrm{D}$. The wind turbines were located along the center line.

Figure 7 shows the response from one isolated wind turbine which is the reference case.

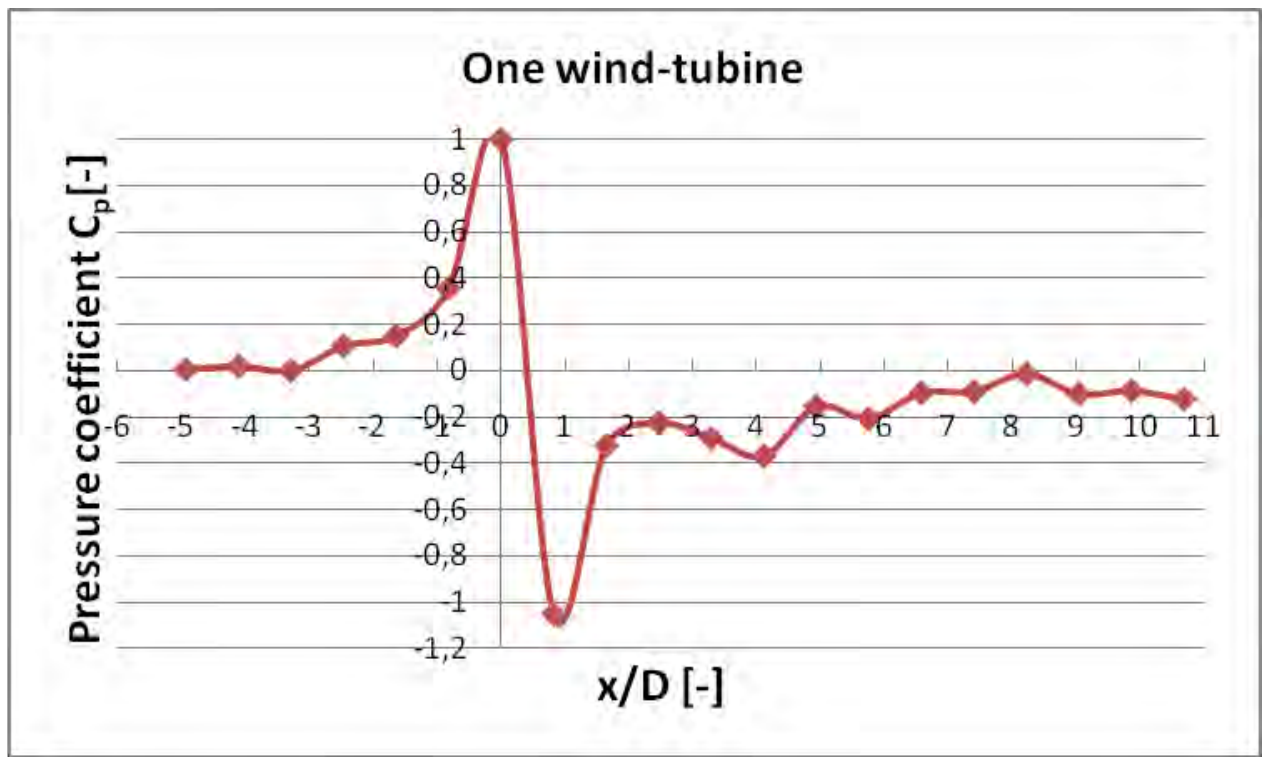

Fig. 7. One undisturbed wind turbine.

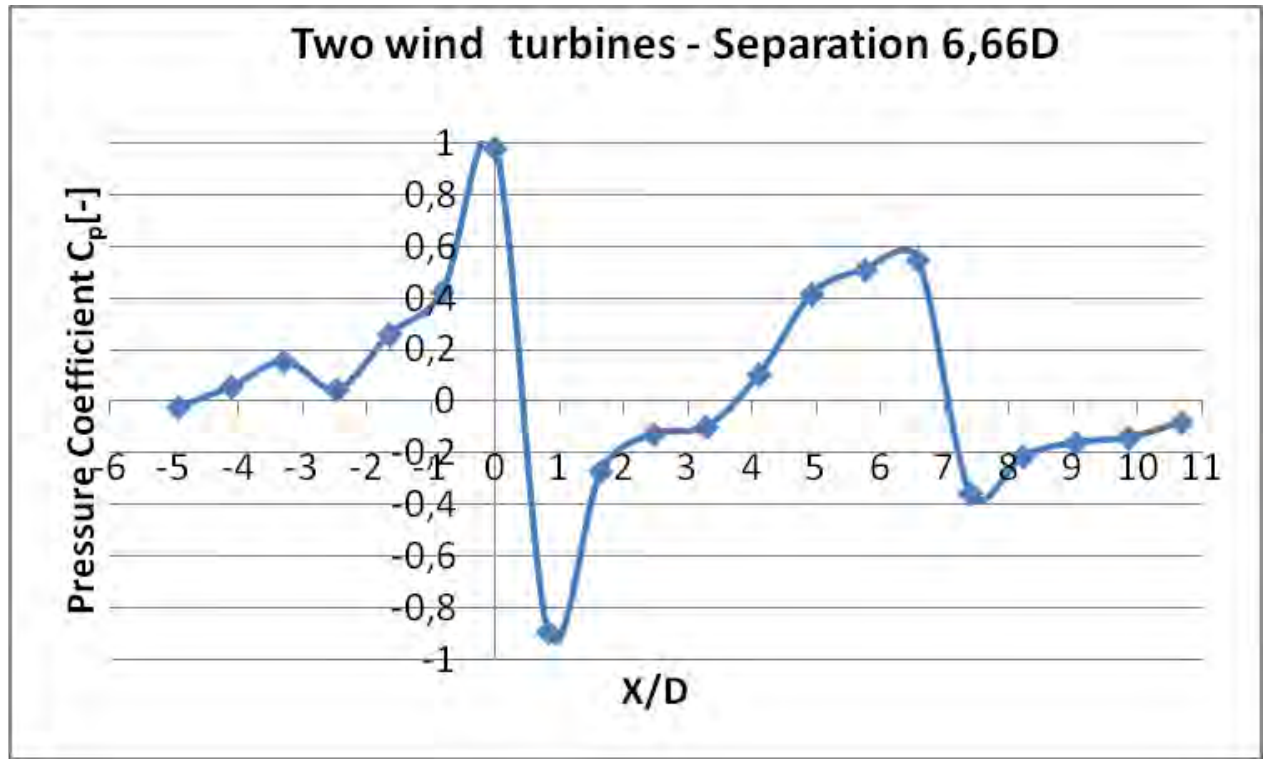

Fig.8 Two wind turbines

By comparing the pressure response of the undisturbed wind turbine in Figure 7 with the pressure response of the wind turbine located downstream in Figure 8 one sees clearly that the wind turbine located downstream is disturbed by the one located upstream. 


\subsection{Comparison between static pressure at hub height and on the plate}

Our method is bases on that that there is a close relationship between the static pressure at hub height and on ground. This has benne tested by measuring the static pressure at hub height with a Prandtl tube. The result is shown in Figure 9.

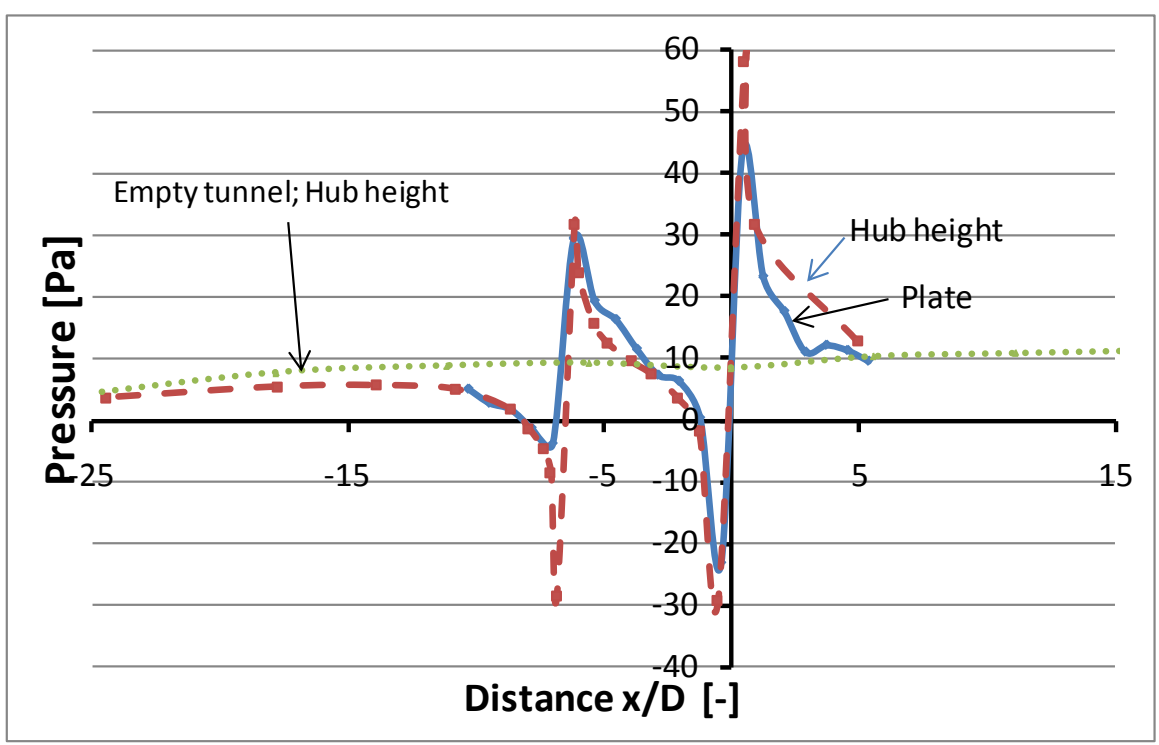

Fig.9 Static pressure at hub height and on ground (pressure plate).

There is a god correspondence between the pressures at the two levels.

\section{Discussion}

There is a clear response in the static pressure on the pressure plate due the presence of wind turbine models. This makes it possible to quantitatively explore the interaction between wind turbines. There is also a good correspondence between the static pressure on the ground (pressure plate) and the static pressure at hub height recorded with a Prandtl tube. Downstream of a wind turbine there is a relatively fast recovery of the static pressure. Therefore the response in static pressure may underestimate the length of the wake in terms of the velocity recovery. This will be explored by measuring the total pressure at hub height and to in detail investigate the velocity field in the wake region with Particle Image Velocimetry.

\section{Conclusions}

This is a new method, which is fast and economic, for exploring the interaction qualitatively between wind turbines. The next step is to develop it into a quantitative method that makes prediction of energy production possible. 


\section{References}

[1] Johnson K. E. and Naveen T (2009). "Wind farm control: addressing the aerodynamic interaction among wind turbines". 2009 American Control Conference, St. Louis,MO,USA, June 10-12.

[2] Ivanell, S. (2009) "Numerical Computations of Wind Turbine Wakes". Doctoral dissertation, KTH, Sweden.

[3] Sørensen, J. N., Mikkelsen, R. \& Troldborg, N. (2007) "Simulation and modelling of turbulence in wind farms”. In EWEC 2007:Milan, European Wind Energy Association.

[4] Wußow, S., Sitzki, L. \& Hahm, T. (2007) "3D simulation of the turbulent wake behind a wind turbine". Journal of physics: Conference series, The science of making torque from wind 75012033.

[5] Kobayashi T, Sandberg M, Kotani H, Claesson L, (2010) Experimental investigation and CFD analysis of cross-ventilated flow through single room detached house model Building and Environment 45pp. pp. 2723-2734

[6] Medici, D. and Alfredsson, P. H. (2005). Wind turbine near wakes and comparisons to the wake behind a disc. ASME Conference, January 2005, Reno, Nevada. AIAA-20050595 